\title{
Revisão da literatura sobre sala de espera e educação em saúde na odontopediatria - novos desafios propostos frente à pandemia
}

\section{Review of the Literature on the waiting room and health education in pediatric dentistry - new chal- lenges proposed in the face of the pandemic}

\section{Revisión de la Literatura sobre sala de espera y educación para la salud en odontología pediátrica - nuevos retos propuestos ante la pandemia \\ Jeovana Laurem de Almeida ${ }^{1 *}$, Carlos Roberto Teixeira Rodrigues ${ }^{2}$, Athaluama Pires da Silva Inocencio $^{3}$, Patrícia Pereira Nogueira ${ }^{4}$}

Como citar esse artigo. de Almeida, JL; Rodrigues, CRT; Inocêncio, APS; Nogueira, PP. Revisão da literatura sobre sala de espera e educação em saúde na odontopediatria - novos desafios propostos frente à pandemia . Revista Pró-UniverSUS. 2021 Jan./Jun.; 12 (1): 66-69

\section{Resumo}

As salas de espera em muitos consultórios e clínicas odontológicas públicas e particulares servem como espaços importantes para o desenvolvimento de atividades de educação, contribuindo para a melhoria da saúde e satisfação da população em relação aos serviços prestados por toda equipe de profissionais. Entretanto, com o advento da Covid-19 e com a nova realidade imposta pela pandemia, novas propostas foram levantadas e colocadas em prática, constituindo ainda, um grande desafio aos cirurgiões dentistas. O objetivo deste artigo foi relatar, através de uma revisão de literatura, os desafios e propostas de ações promocionais de saúde e controle de ansiedade em odontopediatria frente à pandemia do novo Coronavírus. Conclui-se que a brinquedoteca é um espaço que proporciona a interação da criança com a odontopediatra, estimulando seu bem-estar durante a consulta. Entretanto, com a nova pandemia, manter uma agenda com grande espaço de tempo entre um paciente e outro e a utilização de jogos digitais são caminhos fundamentais para manter essa interação e evitar a disseminação do novo vírus.

Palavras-chave: Odontopediatria; Pandemia; Educação em Saúde.

\begin{abstract}
The waiting rooms in many public and private dental offices and clinics serve as important spaces for the development of educational activities, contributing to the improvement of health and satisfaction of the population in relation to the services provided by the entire team of professionals. However, with the advent of Covid-19 and the new reality imposed by the pandemic, new proposals were raised and put into practice, still constituting a great challenge for dental surgeons. The purpose of this article was to report, through a literature review, the challenges and proposals for promotional health and anxiety control actions in pediatric dentistry in the face of the new Coronavirus pandemic. It is concluded that the playroom is a space that provides the interaction of the child with the pediatric dentist, stimulating their well-being during the consultation. However, with the new pandemic, maintaining a long-term agenda between one patient and another and the use of digital games are fundamental ways to maintain this interaction and prevent the spread of the new virus.

Keywords: Pediatric Dentistry; Pandemic; Health Education.
\end{abstract}

\section{Resumen}

Las salas de espera de muchos consultorios y clínicas dentales públicas y privadas sirven como espacios importantes para el desarrollo de actividades educativas, contribuyendo a la mejora de la salud y satisfacción de la población en relación a los servicios que brinda todo el equipo de profesionales. Sin embargo, con la llegada del Covid-19 y la nueva realidad impuesta por la pandemia, se plantearon y pusieron en práctica nuevas propuestas que siguen constituyendo un gran desafío para los cirujanos dentistas. El propósito de este artículo fue dar a conocer, a través de una revisión de la literatura, los desafíos y propuestas de acciones promocionales de control de la salud y la ansiedad en la odontopediatría ante la nueva pandemia del Coronavirus. Se concluye que la ludoteca es un espacio que brinda la interacción del niño con el odontopediatra, estimulando su bienestar durante la consulta. Sin embargo, con la nueva pandemia, mantener una agenda a largo plazo entre un paciente y otro y el uso de juegos digitales son formas fundamentales de mantener esta interacción y prevenir la propagación del nuevo virus.

Palabras clave: Odontopediatría; Pandemia; Educación para la salud.

Afiliação dos autores:

${ }^{1 *}$ Acadêmica no Curso de Odontologia, Universidade de Vassouras. Vassouras, RJ, Brasil. E-mail: jeovana almeida@live.com ORCID: https://orcid.org/0000-0002-2234-6809

${ }^{2}$ Doutor. Docente do Curso de Odontologia, Universidade de Vassouras. Vassouras, RJ, Brasil. E-mail: rodriguescrt@gmail.com ORCID: https://orcid.org/0000-0001-6218-1706

${ }^{3}$ Mestre. Professora do Curso de Odontologia, Universidade de Vassouras. Vassouras, RJ, Brasil. E-mail: athaluamapires@gmail.com ORCID: https://orcid.org/0000-0001-58694357

${ }^{4}$ Mestre. Docente do Curso de Odontologia, Universidade de Vassouras. Vassouras, RJ, Brasil. E-mail: patyppn193@gmail.com ORCID: https://orcid.org/0000-0003-1967-8842 


\section{Introdução}

A especialidade de Odontopediatria, habituada a realizar o controle comportamental do paciente pediátrico e do seu núcleo familiar utilizando a sala de espera como estratégia de controle de ansiedade e ambiente de ações promocionais de saúde, enfrenta um de seus maiores desafios frente à nova pandemia da Covid-19'.

Salas de espera de consultórios particulares, Unidades Básicas de Saúde, Hospitais ou Universidades servem como ambiente de interação entre a família do paciente pediátrico e o próprio paciente com a equipe de Saúde.

Diversos pacientes apresentam diferentes medos antes de entrarem em um consultório odontológico para serem atendidos, sejam eles adultos ou crianças, contudo o atendimento infantil sempre foi mais difícil, quando comparados com o atendimento à adultos, pois socialmente o consultório odontológico é vinculado a experiências dolorosas e desagradáveis, fazendo assim que as crianças fiquem mais ansiosas ${ }^{2,3}$.

A utilização das salas de espera com suas brinquedotecas para crianças, proporcionam a interação com a equipe profissional tirando as primeiras impressões do que o espera quando se sentar na cadeira do dentista. Tais salas, quando bem planejadas, diminuem a ansiedade e o medo, estimulando o bemestar tanto de crianças como dos adultos. Estes locais podem servir também como espaços importantes para o desenvolvimento de atividades de educação para a saúde, contribuindo para a melhoria desses e satisfação da população com os serviços prestados ${ }^{1}$.

Considerando-se, o cenário atual na saúde pública e privada no Brasil e no mundo, imposto pela emergência do novo Coronavírus (COVID-19) algumas alternativas remotas e interativas apresentam grandes potenciais neste contexto, proporcionando menor risco de contágio entre a equipe de Saúde Bucal e seus pacientes4. Além disso, diminui aglomerações em salas de espera e garante a continuidade do trabalho de promoção de saúde e prevenção das doenças, sendo também uma ferramenta de controle de ansiedade frente ao atendimento odontológico ${ }^{4}$.

O objetivo deste artigo foi relatar através de uma revisão de literatura os desafios e propostas de ações promocionais de saúde e controle de ansiedade em Odontopediatria frente à Pandemia da SARS-COV-2 .

\section{Materiais e Métodos}

Estudo elaborado a partir de uma revisão da literatura nas bases de dados Scielo, Medline e Lilacs, no período entre 2005 e 2020. Para a busca foram utilizados os descritores: "Sala de Espera", "Odontopediatria",
"Pandemia", "Educação em Saúde".

Com a busca foram encontrados inicialmente 20 artigos. Após leitura criteriosa dos títulos e resumos, foram incluídos apenas aqueles artigos que guardavam relação direta com o tema proposto. Sendo excluídos aqueles que não apresentavam texto na integra e não diziam respeito ao propósito do estudo. Por fim, foram selecionados 13 artigos que serviram para discussão deste estudo.

\section{Discussão e Resultados}

A promoção do brincar como ação de saúde vem ganhando ênfase, principalmente na hospitalização infantil, tendo maior destaque a partir de 2000 quando o Ministério da Saúde lançou o Programa Nacional de Humanização da Assistência Hospitalar (PNHAH)5. Brincar se tornou um instrumento terapêutico, além de integrar pacientes e equipes de saúde, proporcionando à criança a oportunidade de escolhas e o acesso a uma linguagem que é de seu domínio, fornecendo instrumentos para que esta se coloque como agente ativo do seu tratamento 5 .

$\mathrm{O}$ ato de brincar também pode ser percebido pelos profissionais de saúde como sendo um facilitador no processo de trabalho para se lidar com o sofrimento. Em um contexto geral a sala de espera montada com uma brinquedoteca com jogos, desenhos livres, brinquedos é considerada um local que tem como objetivo primário permitir que a criança brinque, possibilite e estimule a criatividade, a imaginação, a solução de problemas, o desenvolvimento da expressão e da comunicação ${ }^{6}$.

A brinquedoteca consiste num espaço que contém jogos educativos e brinquedos que objetivam estimular o ato de brincar nas crianças7. As atividades lúdicas trazem em si mesmas o papel de fazer vir à tona aquilo que, muitas vezes, por palavras não consegue ser expresso. Existe, portanto, uma estreita relação entre o progresso do tratamento odontopediátrico e o bem-estar do paciente e essa relação ganha maior visibilidade na medida em que as atividades lúdicas são postas em evidência pelo odontopediatra ${ }^{5}$.

No atendimento odontopediátrico os pais também devem colaborar para que o tratamento não marque a vida da criança como algo ruim. Sendo assim, os pais ou responsáveis devem evitar fazer promessas, tais como dar brinquedo, sorvete ou qualquer outro tipo de recompensa caso a criança se comporte bem durante a ida ao dentista, pois isso pode fazer com que a criança intérprete que a consulta odontológica será algo assustador e ruim ${ }^{8}$.

É importante observar que, dependendo de quais jogos e brinquedos são postos na brinquedoteca é possível proporcionar as crianças vivências que acarretam a conscientização da saúde bucal em situações reais como 
escovação, dentes restaurados, lesões cariosas e doenças periodontais, potencializando assim o aprendizado e a conscientização ${ }^{6},{ }^{7,9}$. Além disso, o brinquedo é uma excelente ferramenta que promove a interação entre o dentista e o paciente10, facilitando o trabalho do mesmo, uma vez que, o lúdico faz com que a criança expresse melhor o que está sentindo10, principalmente quando a brinquedoteca possui brinquedos voltados para a área da saúde ${ }^{11,12}$.

Os brinquedos que normalmente compunham a brinquedoteca eram pedagógicos e sua distribuição no ambiente devia possibilitar um fácil acesso a eles, bem como não podiam atrapalhar a circulação da criança e dos orientadores no espaço. Outra questão referente à montagem de um brinquedoteca está na organização de espaços diversos, pois possibilitam atingir os objetivos: aprendizagem e o desenvolvimento das crianças que utilizam esse ambiente13. Cada espaço deve oferecer materiais e atividades de acordo com a faixa-etária das crianças que o utilizam ${ }^{13}$.

No que tange a utilização da brinquedoteca é necessário que os profissionais orientem as crianças de como utilizá-la e estimulá-las a brincar, sendo assim, mostrar como o espaço é organizado e combinar como deve ser utilizado possibilita a manutenção do mesmo ${ }^{10}$. Após ter combinado com a criança como deve utilizar esse espaço é necessário que deixe-a explorar o mesmo e caso haja necessidade auxiliá-la a refletir sobre as possibilidades de uso daqueles brinquedos ${ }^{10}$.

Embora a brinquedoteca apresente em sua composição (antes da pandemia) diversos brinquedos, isso não garante que se tenha bons resultados, pois é necessário que se tenha uma equipe profissional preparada para atuar nesses espaços, sendo fundamental que saiba trabalhar com o lúdico e que seja ciente do seu papel junto às crianças no contexto da brinquedoteca ${ }^{13}$. Outro ponto importante é que não existe um padrão de brinquedoteca a ser seguido, mas sim uma singularidade de brinquedotecas que são equipadas de acordo com o local em que são instaladas ${ }^{13}$. Como visto até o momento, o conceito da brinquedoteca é repleto de objetos e se apresenta como uma excelente ferramenta de interação entre o dentista e a criança, além de ser um ambiente de aprendizagem. Porém, devido a Pandemia da COVID-19, alguns órgãos vêm aconselhando que as salas de espera não aglomerem pacientes e que os horários de atendimento possuam grandes espaços entre um paciente e outro e sempre com a utilização das máscaras. Outros órgãos, recomendam que as salas de esperas devem ser higienizadas duas vezes por turno, como por exemplo maçanetas, cadeiras etc. ${ }^{15}$.

Algumas clínicas odontológicas fazem uso da brinquedoteca para promover atividades que possuem como objetivo mostrar a importância da saúde bucal e promover conhecimento, não só com as crianças, mas também com os responsáveis, além de influenciar no tratamento odontopediátrico, a brinquedoteca pode tornar a estadia da criança na clínica menos estressante ${ }^{16}$.

A brinquedoteca geralmente é instalada na sala de espera edeve ser tambémumambiente de conscientização sobre os cuidados bucais e para isso pode utilizar pequenos filmes animados, cartazes, panfletos, atividades artísticas e brincadeiras. É importante que os brinquedos que irão compor uma brinquedoteca sejam aqueles desenvolvidos por empresas do ramo odontológico, uma vez que esses através do lúdico, enfatizam de forma positiva a odontologia e a prevenção de doenças bucais, além de fazer com que a criança colabore mais, pois os brinquedos são ótimos intermediários entre a criança e o dentista, visto que essa relação é fundamental entre $\operatorname{ambos}^{15}$. É importante ressaltar que esses ambientes influenciam de forma positiva no tratamento clínico das crianças não só ajudando na recuperação, mas também permitindo que elas expressem melhor os sintomas que estão sentindo, por meio do lúdico ${ }^{10}$. Nesse contexto a atividade lúdica torna-se uma ferramenta imprescindível para a odontopediatra, pois por meio desse mecanismo é possível criar um vínculo afetivo entre o dentista e o paciente infantil, acarretando assim em uma melhor adesão do tratamento por parte da criança ${ }^{5,16}$.

A brinquedoteca pode reduzir a ansiedade e estresse das crianças durante a consulta odontológica sendo assim esse é um dos grandes benefícios oriundos da implantação de uma sala de recepção com brinquedoteca equipada com brinquedos voltados para a área da saúde ${ }^{11}$.

Deve-se entender a brinquedoteca como um ambiente puramente lúdico e capaz de fazer com que o tratamento odontológico seja prazeroso para a criança, contudo não deve ser vista como ferramenta mediadora extremamente eficaz entre a odontopediatra e a criança, pois ela não é cem por cento eficaz, mas de modo geral ela é capaz de proporcionar momentos felizes na criança, tornando assim as práticas odontológicas mais humanizadas ${ }^{11,12}$.

Em meio a essa pandemia, em que o vírus se encontra em objetos, como a brinquedoteca deva ser operacionalizada? Não é possível criar afirmações, mas apenas apontar caminhos para que facilite a interação entre odontopediatra e a criança. Uma das formas que isso pode ocorrer é criando uma brinquedoteca digital, ou seja, que as crianças possam utilizar a partir dos seus próprios meios eletrônicos. É importante que não fuja dos objetivos das brinquedotecas físicas, sendo assim deve possuir atividades que possibilitem o aprendizado sobre saúde bucal e que ao mesmo tempo possam se divertir. Uma das alternativas que emerge seria uma interação entre a odontopediatra e a criança por meio de videoconferência e um diálogo amigável e divertido. Uma questão que pode ser viável, quando o meio virtual não for possível de ser utilizado, consiste no agendamento de crianças para serem atendidas com 
espaço de tempo considerável e deixar na brinquedoteca apenas os brinquedos de fácil higienização, como por exemplo os brinquedos de plástico ou até mesmo óculos de realidade virtual que apresentem atividades relacionadas a saúde bucal ${ }^{17}$.

\section{Considerações Finais}

O estudo buscou relatar através de uma revisão de literatura, desafios e propostas de ações promocionais de saúde e controle de ansiedade em odontopediatria frente à pandemia do novo Coronavírus.

Por meio da literatura disponível, de artigos já publicados, pôde-se verificar que a brinquedoteca pode ser um espaço que permite a criança se desenvolver e aprender sobre hábitos saudáveis de cuidado com saúde, bem como facilitar a relação entre a odontopediatra e o paciente. Além disso esses ambientes podem reduzir a ansiedade das crianças antes que esse entre no consultório do dentista.

Devido apandemiadaCOVID-19 odontopediatras devem recorrer a outros meios para que a criança se sinta confortável antes do seu atendimento, como por exemplos brinquedos e jogos digitais ou até mesmo escolher brinquedos de fácil higienização. E uma questão importante é manter uma agenda de atendimento com grandes espaços entre uma criança e outra.

\section{Referências}

1. B1. Casamassimo P, Castellano J, Conte C, Czerepak C, Jacobson B, Lee J, Miller J, Younger L. Re-emergence pediatric: dentistry practice checklist. 2020; New York, America’s Pediatric Dentists.

2. Possobon RF, Carrascoza KC, Moraes ABA, Costa Júnior, ALC. O tratamento odontológico como gerador de ansiedade. Psicologia em Estudo. 2007; 12(3): 609-616.

3. Leite DFBM, Muniz IAF, Farias IAP. Condução psicológica do paciente infantil em Saúde Pública. Odontol. Clín.-Cient. (Online) [online], 2013; 12(4): 251-254.

4. ABENO, Associação Brasileira de Ensino Odontológico. Consenso Abeno: biossegurança no ensino odontológico pós-pandemia da Covid-19. ABENO. 2020; Porto Alegre.

5. Oliveira JCC. Atividades lúdicas na Odontopediatria: uma breve revisão da literatura. Rev. bras. odontol. 2014; 71(1): 103-107.

6. Barbosa JLV, Mialhe FL, Morano JM, Gonçalo CS. utilização da brinquedoteca como espaço terapêutico e de práticas de educação em saúde. Revista UNINGA. 2007; 20(14): 153-160.

7. Reis LBM, Franco LLMM, Romanowski FNA, Amaral DC. A Brinquedoteca na Clínica odontológica de ensino do Centro Universitário de Anápolis. In: Anais do III CIEPEEX. 2018; Anápolis.

8. Colares V, Pinkham J. "Domínio Lingüístico": uma nova perspectiva na abordagem do paciente infantil. JBP jornal brasileiro de odontopediatria \& odontologia do bebê. 2001; 4(22):497-500.

9. Oliveira TJS, Santos AA, Santos TJ. Jogos educativos - mudança no hábito de higienização bucal. Odontol. Clín.-Cient. 2002; 2(1): 123-128.

10. Carneiro MAB. Brinquedos e brincadeiras: formando ludoeducadores. São Paulo: Articulação/ Universidade Escola, 2003.
11. Carmo MCP et al. Explorando o lúdico e a humanização com a brinquedoteca no atendimento odontológico na clínica infantil. In: Anais da Jornada Odontológica (JOA) de Anápolis. 2019; Anápolis.

12. Amante $\mathrm{CJ}$ et al. $\mathrm{O}$ brinquedo como recurso mediador para $\mathrm{o}$ atendimento odontológico de pacientes com necessidades especiais. Revista Ciências da Saúde. 2008; 27(1): 21-26.

13. Azevedo ACP. Brinquedoteca no diagnóstico e intervenção em dificuldades escolares. 2010; Campinas: Alínea.

14. Pires AMB, Fonseca CRB. A importância do atendimento ambulatorial pediátrico em tempos de covid-19. Acesso em 22 de junho de 2020. Disponível em:https://www.spsp.org.br/2020/03/20/medidas-para-opediatra-relacionadas-com-a-pandemia-do-covid-19/

15. Associação Brasileira de Dermatologia (ABD). Prevenção à Covid19: SBD divulga recomendações aos dermatologistas para evitar o risco de contaminação em locais de atendimento. Acesso em 22 de junho de 2020 Disponível em: https:/www.sbd.org.br/noticias/prevencao-a-covid-19sbd-divulga-recomendacoes-aos-dermatologistas-para-evitar-o-risco-decontaminacao-em-locais-de-atendimento/.

16. Emmi DT, Pires MJM. Acolhimento e educação em saúde na sala de espera: avaliação da contribuição das ações para o atendimento odontopediátrico. Rev. Aten. Saúde. 2016; 14(48): 62-67.

17. Mallieni NPI et al. Coronavirus disease (COVID-19): Characteristics in children and considerations for dentists providing their care. International Journal of PePediatric Dentistry. 2020; 30(3): 245-250. 